\title{
Accuracy of the pneumatic follower for the wooden surface quality assessment
}

\author{
Cz. J. Jermak ${ }^{1} \cdot$ M. Rucki ${ }^{2}$ (D) M. Jakubowicz ${ }^{3}$
}

Received: 1 October 2019 / Published online: 28 August 2020

(c) The Author(s) 2020

\begin{abstract}
Wooden or wood-plastic composite surfaces are often valued for their aesthetic appearance and the quality of the surface. Independent from the technology, the surface features may be assessed using typical roughness parameters. In this paper, a pneumatic non-contact method is proposed. Despite certain limitations in surface characteristics measurement, air gauges proved to be a good tool for wooden surfaces, much cheaper than the laser profilometers. In the current research, a novel non-contact air gauge was combined with a slider to eliminate the influence of the asperities of higher order (waviness) and to protect the wooden surface from being damaged by the measuring nozzle. The measurement signal was used to control a follower that kept constant distance between the surface and the nozzle edge. The measuring speed was set at $0.8 \mathrm{~mm} / \mathrm{s}$, and the back-pressure was measured with accuracy of $0.01 \mathrm{kPa}$ with real time acquisition. A series of measurements was taken, and the results were compared with the ones obtained from Perthen S8P profilometer (contact measurement) and WYKO NT 1100 interferometer microscope.
\end{abstract}

\section{Introduction}

Surface quality of the machined wood is one of the most important characteristics that has impact on further manufacturing processes, such as finishing, and subsequently effects on the strength of adhesive joints etc. (Aguilera et al. 2016). Wooden or wood-plastic composite (WPC) surfaces are often valued for their aesthetic appearance, for example, in the case of furniture. In both cases the appearance depends on the quality of the surface, which must be machined and finished in a proper way. Among the most common methods of shaping the wooden surface are cutting, laser treatment,

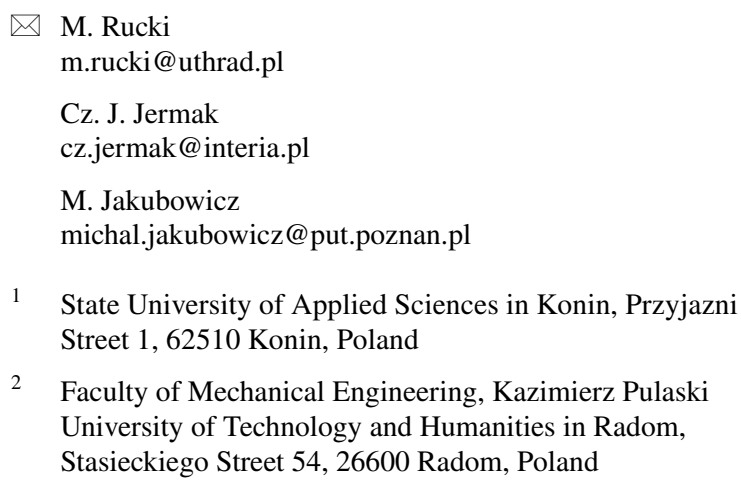

1 State University of Applied Sciences in Konin, Przyjazni Street 1, 62510 Konin, Poland

2 Faculty of Mechanical Engineering, Kazimierz Pulaski University of Technology and Humanities in Radom, Stasieckiego Street 54, 26600 Radom, Poland

3 Division of Metrology and Measurement Systems, Poznan University of Technology, Piotrowo 3, 60965 Poznan, Poland chemical finishing, impregnation and other treatments aimed at rheological properties. Recently, propositions and investigations on plasma modification of the wooden surface were reported (Peng and Zhang 2019). Independent from the technology, the surfaces may be assessed by means of roughness parameters, such as mean peak-to-valley height $R z$, usually referred to as ten-point height, and average roughness $R a$ commonly known as arithmetic mean deviation, according to the ISO 4287 (1997) standard (Jarusombuti and Ayrilmis 2011). It should be noted, however, that the methods and parameters applied to the measurement of the metal surface features, are not always applicable in the case of wood. Specifically, the parameters related to the load-bearing capacity and lubrication performance are of seldom interest in wood technology, while they are very important in the metal industry (Csanády et al. 2015).

Many authors addressed the issue of the wooden surface measurement (Zhong et al. 2013). Because of the need of non-contact measurement, the automatic measurement based on laser imaging was proposed (Hu and Afzal 2005). Aguilera and Barros (2010) suggested to analyze the sound pressure in order to assess and predict the surface roughness. Other authors reported good correlation between results of the contact measurement with stylus and 3D scanning of a wooden surface (Zhong et al. 2013). In the current project, the pneumatic method is applied, which 
is much cheaper than a laser profilometer but ensures the non-contact measurement.

Air gauges have been used for dimensional measurement for almost a century. Their applications to roughness assessment are documented as early as in 1937 (Fullmer 1966), but they are still subject of scientific interest (Wieczorowski 2013). Despite certain limitations in surface characteristics measurement, air gauges proved to be a good tool for profile measurement and out-of-roundness assessment both in dynamic (Jermak and Rucki 2016a) and in static perspective (Jermak and Rucki 2016b). These devices may have either analog or digital displays (Bewoor and Kulkarni 2009), and many companies today offer the air-electronic solutions in their catalogues. There are also recent reports on air-gauging applications to laboratory measurement (Meng et al. 2014). Their application to the wooden surface assessment seemed to be promising and reasonable (Pohl and Jermak 2007), and the current work provided a good basis for wooden surface assessment with air gauges playing the main role in the novel follower-type measurement system.

\section{Principle and properties of air gauging}

The operation of air gauges is based on the flow phenomena through the restrictions. The pressurized air while escaping from the jet is impeded by impinging against a surface of the measured detail, so the distance between the surface and air escape opening has effect on the air flow velocity and creates back pressure (Farago and Curtis 2014). The authors emphasized that the open jet type air gauges are sensitive to the geometry of the measured surface, thus, in dimensional measurements, the setting masters must have similar surface geometry to the measured object.

The energy balance of the airflow with parameters lower than critical values through the air gauge elements can be written as follows (Zelczak 2002):

$\frac{p_{z}}{\rho_{z}}-\left(\frac{v_{1}^{2}}{2}+\frac{v_{s}^{2}}{2}\right)-\left(\frac{v_{1}^{2}}{2} \xi_{1}+\frac{v_{2}^{2}}{2} \xi_{2}+\frac{v_{s}^{2}}{2} \xi_{s}\right)-\frac{p_{a}}{\rho_{a}}=0$

where $p_{\mathrm{z}}, p_{a}$-feeding pressure and atmospheric pressure, respectively, $\rho_{\mathrm{z}}, \rho_{a}$-the volumetric mass density of feeding pressured air and air outside the system, respectively, $v_{1}, v_{2}$, $v_{s}$-air stream velocity in the inlet nozzle, inside the measuring nozzle and in flapper-nozzle area, respectively, $\xi_{1}, \xi_{2}$, $\xi_{s}$ - energy losses in the inlet nozzle, inside the measuring nozzle and in flapper-nozzle area, respectively.

In real conditions, however, four possible combinations of the flow rates compared to the critical value $\beta_{k r l}$ can occur, namely (Balakshin 1964):
1. inlet nozzle pressure ratio is $\beta_{w}>\beta_{k r l}$ and in the flappernozzle area $\beta_{p}>\beta_{k r l}$, too;

2. in the inlet nozzle $\beta_{w}<\beta_{k r l}$ while in the flapper-nozzle area $\beta_{p}>\beta_{k r l}$;

3. in the inlet nozzle $\beta_{w}>\beta_{k r l}$ while in the flapper-nozzle area $\beta_{p}<\beta_{k r l}$;

4. ratio in the inlet nozzle $\beta_{w}<\beta_{k r l}$ and in the flapper-nozzle area $\beta_{p}<\beta_{k r l}$ as well.

When the second critical parameter (SCP) is taken into account, calculations provide much better approximation of the static characteristics than other models, with an approximation error of ca. 5\% and even smaller in the proportional area (Jermak et al. 2017c).

The ability of air gauges to measure average roughness between $R a=0.1 \mu \mathrm{m}$ and $R a=5 \mu \mathrm{m}$ is known for decades (Smith 1994). There are numerous merits of air gauging, many of them are important for the wooden surface measurement, such as (Farago and Curtis 2014):

- Simple and cheap construction of gauging heads, even those dedicated to individual measuring tasks;

- Insensitivity to the outer dirt;

- Non-contact measurement and small force on the measured surface;

- Self-cleaning of the measured surface;

- Easy adjustment of the metrological characteristics;

- In most applications, dynamical characteristics are good enough, and may be improved (Jermak and Rucki 2016a).

The ranges of "roughness" and "waviness" typical for Geometrical Specification (ISO 1997) are not always applicable to the wood industry. In the case of wood, an asperity should not be classified as a roughness just because it makes a proportion of, for example, 50:1. Sometimes it is required to apply individual cutoff $\lambda_{c}$ for roughness and waviness (Raja et al. 2002). In practice, two or three characteristics of the surface must be identified and measured, dependent on the stage of its forming process. It is often required to assess some ranges of the asperities and to omit all the other surface characteristics. It is reported that the most frequent choice of profile measurement is a stylusbased contact instrument, which equates to ca. $40 \%$ of the publications (Townsend et al. 2016). However, in the case of delicate wooden and wood-based materials, surface quality assessment may appear to require a non-contact method. On the one hand, a stylus may damage its structure, but on the other hand, too low a force may cause that the stylus will not stay reliably in contact with the surface (Leach 2001). Deformation provides erroneous results, and the scratch on the wooden surface affects its appearance. However, some studies prove that the stylus is better suited to detect surface irregularities than the laser (Gurau et al. 2001), and 
despite some limitations, stylus tracing remains the most accurate measuring technique for wooden surfaces (Molnar et al. 2017).

The applied air gauge was of the back-pressure type, where the airflow is restricted by the slot $s$ between the gauge head and the measured surface, and the pressure $p_{k}$ in the chamber is the measure of the surface asperity (Jakubiec and Malinowski 2009). Figure 1 (left) presents the scheme of a typical back-pressure air gauge supplied with pressured air of a pressure $p_{z}$, with the measuring chamber (measurement of the back-pressure $p_{k}$ between inlet and measuring nozzles $d_{w}$ and $d_{p}$, respectively. The measurement is possible because of a linear area of the function $p_{k}=f(s)$, as shown in Fig. 1 (right).

The value measured by the air gauge is the back-pressure $p_{k}$, which is converted and obtained as an electronic signal in most recently produced devices. It is recalculated into the slot width value $s$ using the following formula:

$s=\frac{p_{s p}-p_{k}}{K}+s_{p}$

where $s(\mu \mathrm{m})$-is the actual slot width, $p_{s p}(\mathrm{kPa})$-is the back-pressure corresponding to the beginning of the measuring range, $p_{k}(\mathrm{kPa})$ - is the actual back-pressure in the measuring chamber between the measuring and inlet nozzles, $K(\mathrm{kPa} / \mu \mathrm{m})$ - is the multiplication (sensitivity) of the air gauge, $s_{p}(\mu \mathrm{m})$ - the slot width corresponding to the beginning of the measuring range.

As seen in Fig. 1, when the measuring nozzle diameter is too large compared with the measured asperities, the obtained result is erroneous. To avoid that, two sets of measuring nozzles were prepared for the experimental researches, of larger diameters (from 0.5 up to $1.2 \mathrm{~mm}$ ) and of smaller ones (below $0.5 \mathrm{~mm}$ ). In the latter case, such nozzles are untypical, they could be easily damaged, and their metrological characteristics should be additionally examined thoroughly. Figure 2 presents the measuring ranges $z_{p}$ and
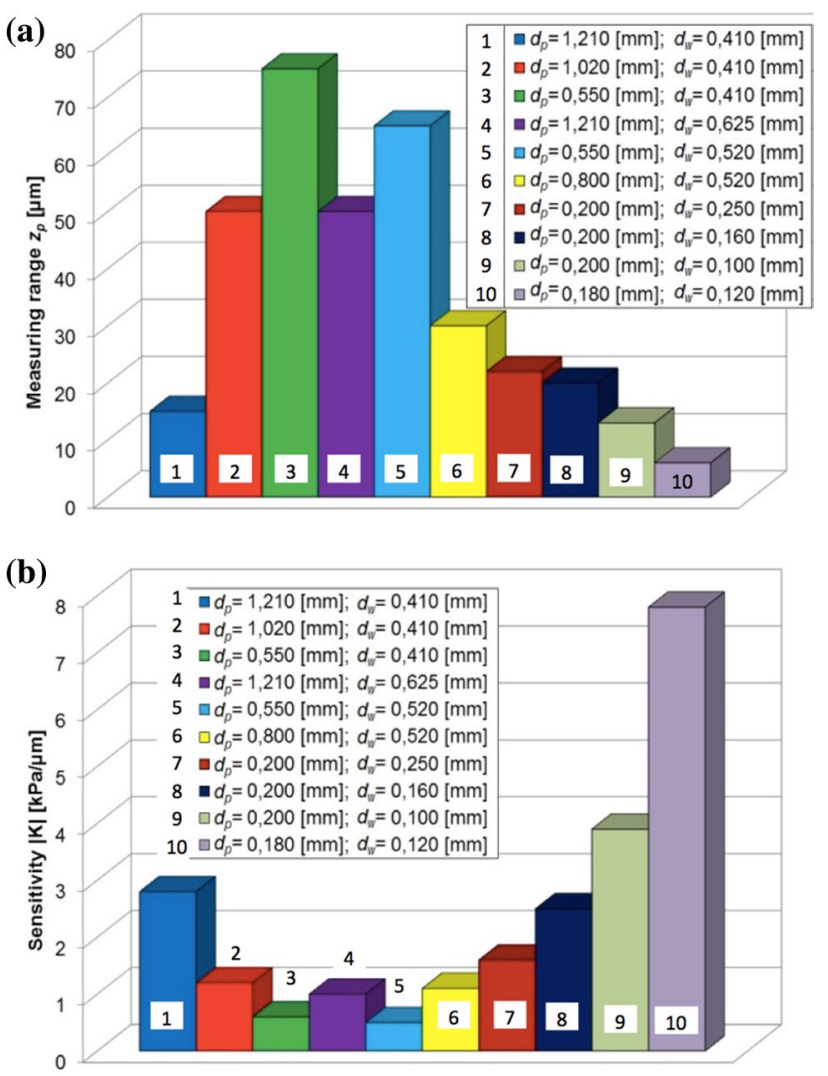

Fig. 2 Metrological properties of the air gauges: measuring range $z_{p}$ (a) and sensitivity $|K|(\mathbf{b})$

static sensitivities $|K|$ of the air gauges with abovementioned measuring nozzle dimensions.

The static characteristics of the air gauges of the configurations presented in Fig. 2 were determined experimentally using the dedicated experimental rig with known uncertainty (Jermak et al. 2017a). It was assumed that the approximation function was acceptable if its linearity $\delta \approx 1 \%$, calculated as follows:
Fig. 1 Back-pressure air gauging principle (left) and its characteristics (right)
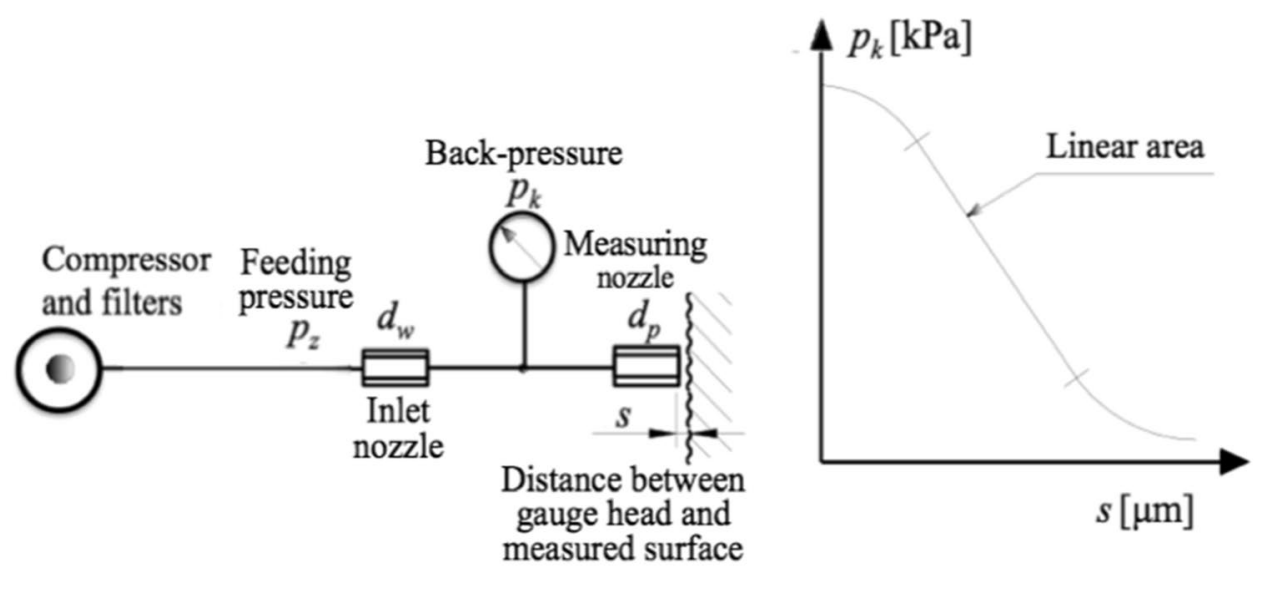
$\delta_{\max }=\frac{\left|\Delta s_{i}\right|_{\max }}{s_{\max }-s_{\min }} \cdot 100 \%$

where $s_{\max }$ and $s_{\min }$-are minimal and maximal slot widths of the considered range, respectively, $\Delta s_{i}$-is the $i$ th difference between the approximated and actual slot width.

\section{Description of the measurement system prototype}

The profile features are recorded with a follow-up method, where the distance between the measured surface and the nozzle is kept constant. In practice, that means the constant back-pressure is kept due to the movement of the air gauge up and down when the asperities cause larger or smaller slot width $s$ during the motion of the air gauge along the measured surface. The structure of the device prototype of the follower type is presented in Fig. 3. It consists basically of the air gauge fed with pressured air through the pneumatic equipment and put in motion by the mechanical equipment. The dedicated device performs control and data acquisition functions. A view of the prototype is presented in Fig. 4.

Figure 5 shows the measurement procedure performed by the device.

The operating principle is as follows: during the movement along the surface, the digital module with A/D converter performs control of the constant air gauge's backpressure value $p_{k}$, which is achieved by the up and down movement compensating increase or decrease in the slot width $s$, i.e. keeping the measuring nozzle at constant distance from the surface. AVR controller module is a central unit that performs data processing and respective control operations using below devices:

- microcontroller module (AT mega 128),

- main desk module with a direct current motor controller,

- pressure transducer module with A/D converter,

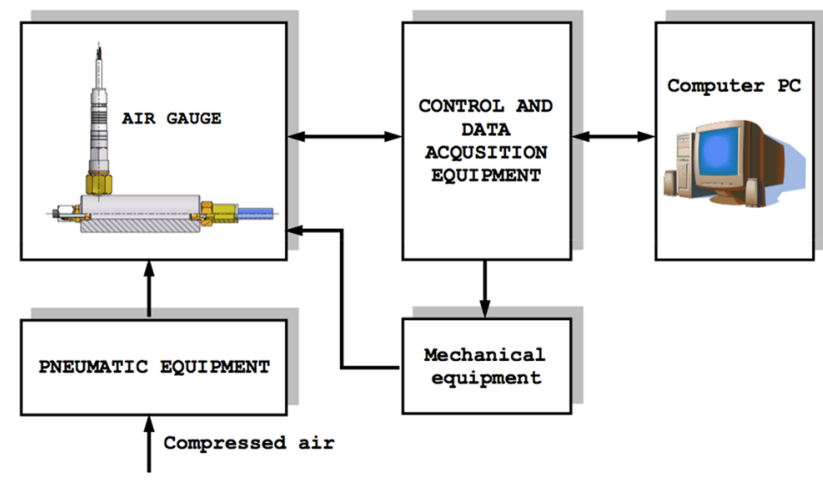

Fig. 3 Structural scheme of the pneumatic follower for surface quality assessment

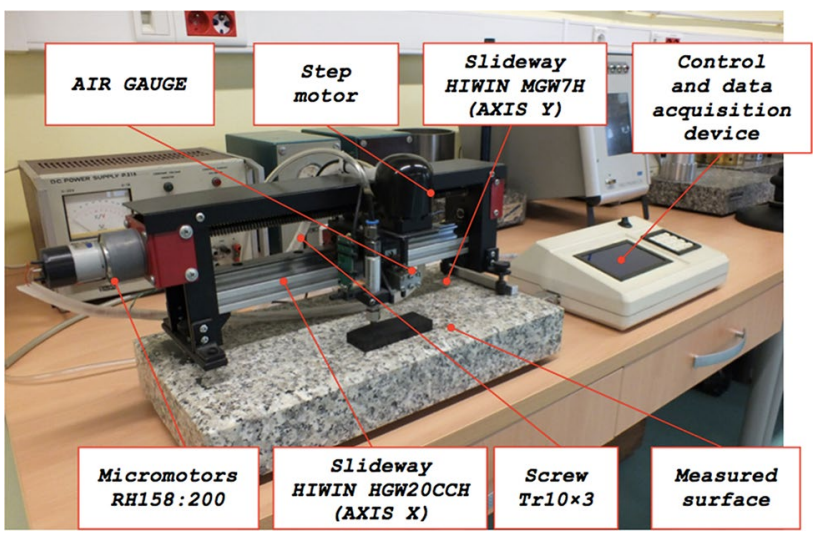

Fig. 4 Details of the pneumatic follower for surface quality assessment

- step motor controller module,

- module of the angle position sensors based on Hall effect ( $\mathrm{X}$ and $\mathrm{Y}$ axes).

The experiments were performed using the air gauge configurations involving both typical and reduced diameters of the measuring nozzle $d p$. Based on a previous study (Rucki and Jermak 2012), the measuring chambers were of small volume $V_{k}$ below $3 \mathrm{~cm}^{3}$ in order to achieve appropriate dynamic characteristics. The examples of the metrological characteristics of the examined air gauges are presented in Table 1 and graphically in Fig. 6.

In general, the air gauges with reduced nozzles diameters (below $0.5 \mathrm{~mm}$ ) have rather short measuring ranges but they are more sensitive to the surface asperities. An additional economic merit of the smaller diameter air gauges is saving the pressured air, so in future designs, they have potential to replace the typical dimension configurations.

The results obtained in form of points representing the measured profile are further processed with the dedicated software. Basic roughness parameters are calculated, such as $R a, R z, R q, P t, W t$, and the profile is presented graphically. Moreover, the amplitude density function and material ratio are calculated and presented graphically, and the final results are exported as a *.doc file.

\section{Results and discussion}

Wooden surface topography is highly depending on the machining process (Kilic et al. 2006) and species characteristics (Thoma et al. 2015). Evenly coated surface characteristics are dependent on the cutting conditions (Souza et al. 2019). For this research, two samples were made modeling different types of surfaces after different technological processes, in order to keep as closest as possible to the 


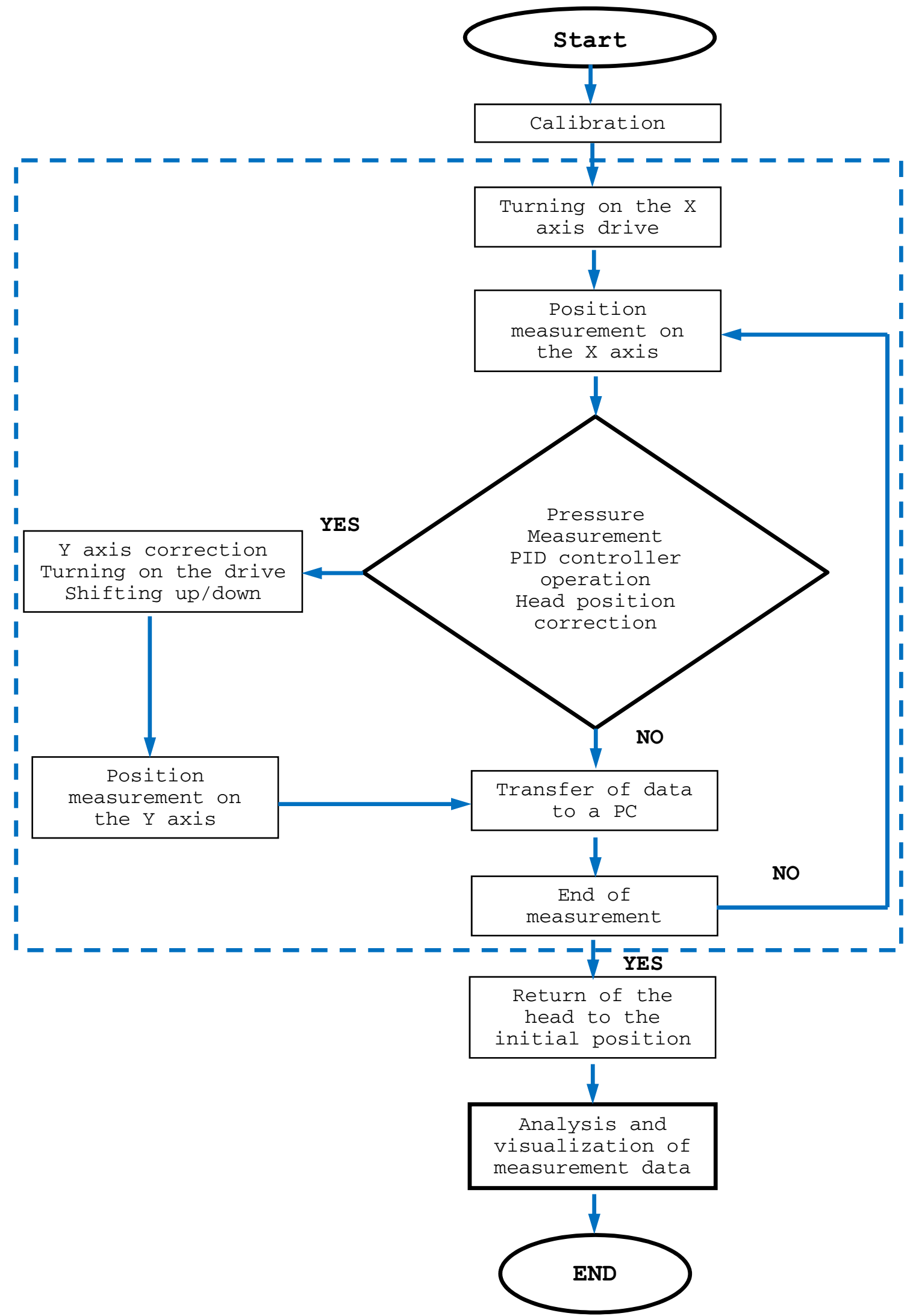

Fig. 5 Measurement procedure algorithm 
Table 1 Metrological characteristics of the air gauges applied to measure wooden samples (Jermak et al. 2017b)

\begin{tabular}{llllll}
\hline $\begin{array}{l}\text { No } \\
\begin{array}{l}\text { nozzle } d_{p} \\
(\mathrm{~mm})\end{array}\end{array}$ & $\begin{array}{l}\text { Inlet } \\
\text { nozzle } d_{w} \\
(\mathrm{~mm})\end{array}$ & $\begin{array}{l}\text { Pressure } \\
\text { range }(\mathrm{kPa})\end{array}$ & $\begin{array}{l}\text { Measuring } \\
\text { range } z_{p} \\
(\mu \mathrm{m})\end{array}$ & $\begin{array}{l}\text { Sensitivity } \\
K(\mathrm{kPa} / \\
\mu \mathrm{m})\end{array}$ \\
\hline 1 & 1.020 & 0.410 & $130-80$ & 50 & 1.2 \\
2 & 0.550 & 0.410 & $140-110$ & 75 & 0.6 \\
\hline
\end{tabular}

(a)
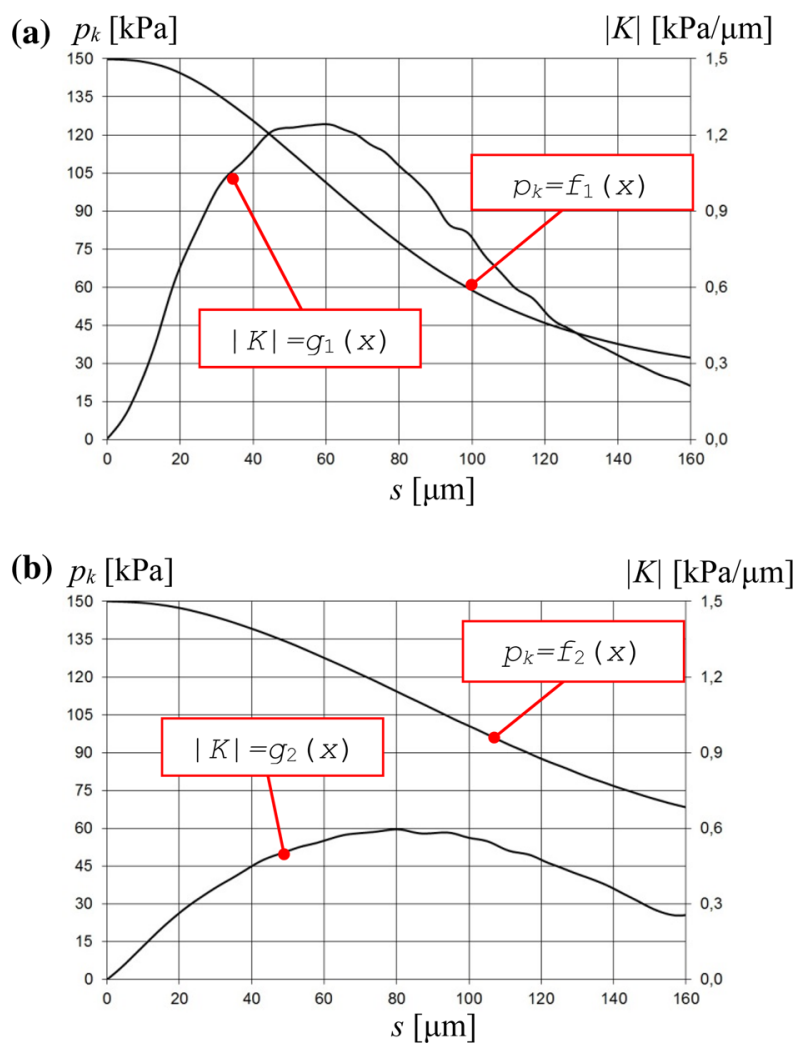

Fig. 6 Metrological characteristics of the air gauges no. 1 (a) and 2 (b) specified in Table 1

real conditions of measurement. Below are the numbers of specific samples:

1. sample made of beech wood after the machining by the band saw, with shape errors generated after drying,

2. sample made of beech wood with surface shaped by the frame saw.

Metrological analysis included comparison with the results obtained from two reference devices, which were the Perthen S8P profilometer and the microscope NT1100 (Veeco Instruments). Perthen S8P profilometer was equipped with the stylus of angle $45^{\circ}$ and tip radius $2 \mu \mathrm{m}$, with a force $0.8 \mathrm{~N}$. The measurement was taken at a speed of $100 \mu \mathrm{m} / \mathrm{s}$, the sampling length was $56 \mathrm{~mm}$, and evaluation length was
$40 \mathrm{~mm}$ with 8064 probing points. Range of the vertical measurement was $500 \mu \mathrm{m}$ with 16,324 probing points, and a roughness cut-off of $8.0 \mathrm{~mm}$ was applied.

NT1100 enabled measurement in the vertical range from 0.1 to $1 \mathrm{~mm}$ with repeatability $0.01 \mathrm{~nm}$. Figures 7 and 8 show the results obtained for the samples 1 and 2, respectively, also considering the effect of the feeding pressure. These results represent only the air gauge no. 1 as an example, but later, in the overall analysis, no. 2 is discussed as well. It can be noted that the measurement results of roughness parameters tend to be higher for higher feeding pressure, but it is not a rule.

As easily predictable, in general, the air gauges configurations with the nozzles of larger diameters provided less accurate results. Figure 9 illustrates the difference between the registered and the actual peaks during the measurement of a sharp peak with the air gauge. As in the case of a stylus of larger diameter, the mechanical filtering takes place (Pawlus 2004), which is not always undesirable, though. For some wooden surfaces it appears to be an advantageous characteristics, although it poses some limitations on the applicability of the device.

From Figs. 7 and 8 it can be seen that in some cases, the results of pneumatic and stylus measurement are very close to one another, while in others they differ substantially. Considering the Perthen contact measurement as a reference, the so-called relative experimental error of method $\delta_{\text {em }}$ can be calculated from formula (4) as follows (Adamczak 2008):

$\delta_{e m}=\frac{\Delta Z_{m}-\Delta Z_{a}}{\Delta Z_{a}} \cdot 100 \%$

where $\Delta Z_{\mathrm{m}}$ and $\Delta Z_{\mathrm{a}}$-are the compared parameters obtained from the examined device and from the reference one, respectively.

Interestingly, for each measured parameter $\mathrm{Wt}, \mathrm{Pt}, \mathrm{Ra}$, $R q$ and $R z$, the relative error of method $\delta_{e m}$ appeared to be different. Figure 10 presents the set of graphs illustrating the issue for the air gauge no. 2 with different feeding pressures $p_{z}$ from 90 to $110 \mathrm{kPa}$.

The most important observation from the graphs is the impact of feeding pressure. The general trend is that for higher pressure, the relative error is rather smaller, which was the case for $R a, R q$ and $W t$. Parameter $P t$ remains almost unaffected, but $R a$ relative error is the highest for $p_{z}=110 \mathrm{kPa}$, where $\delta_{e m}=35 \%$.

It could be expected that the relative error of the method $\delta_{e m}$ would not exceed $20 \%$. However, only one measurement provided such level of conformity with the reference method, and it was sample no. 2 measured with the air gauge No. 1. Relative errors are shown in Fig. 11, where the smallest is $\delta_{e m}=5 \%$ for $R z$, and the highest is $\delta_{e m}=18 \%$ for $R a$.

In fact, the relative error of method should not be considered a decisive factor in case of surface assessment. 
Fig. 7 Measurement results for the sample no. 1: a with WYKO NT 1100 , b with air gauge no. 1 for different feeding pressures and with Perthen S8P, c Wt, $P t, R a, R q$ and $R z$ parameters obtained from air gauges with reference to Perthen S8P (a)
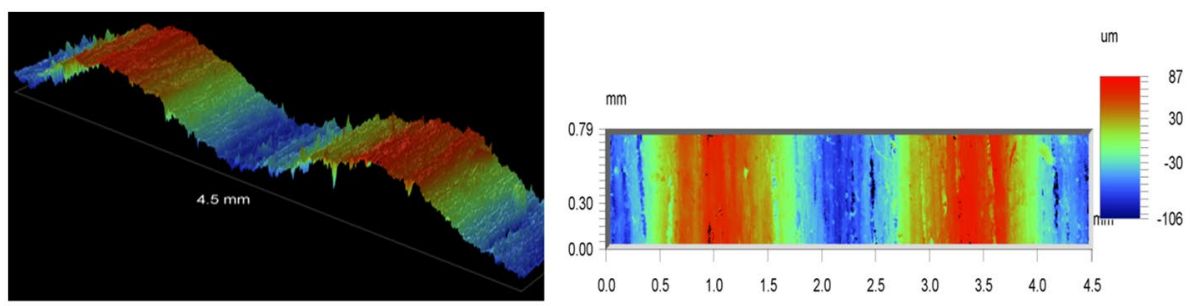

(b)
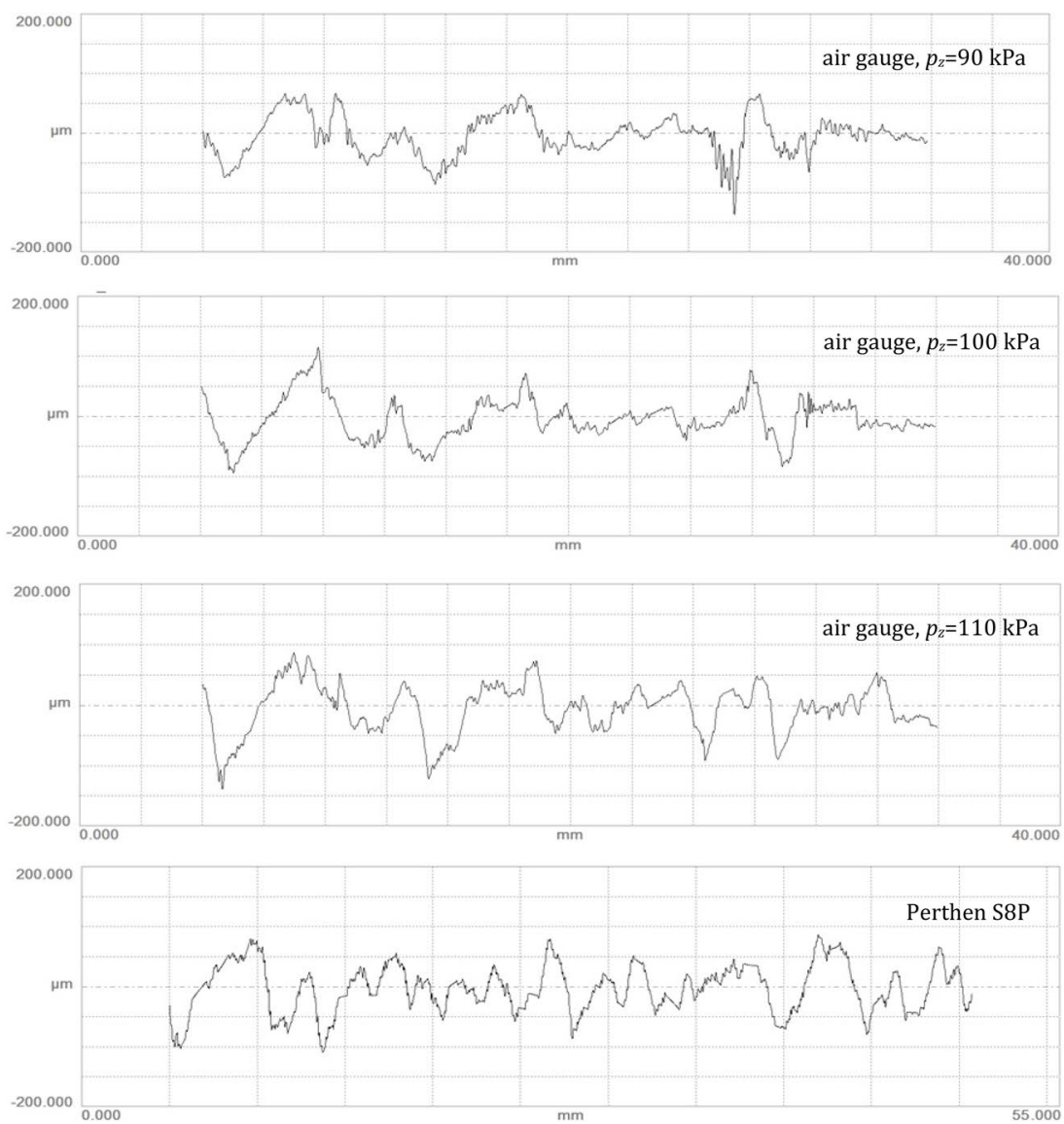

(c)
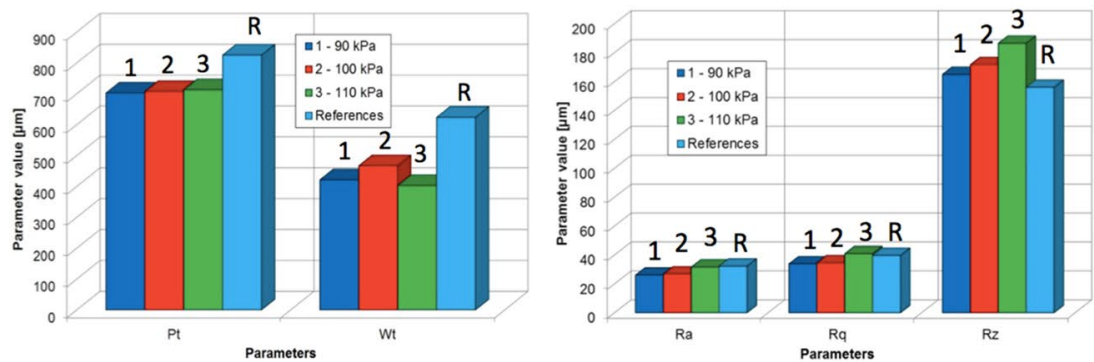

There are numerous published reports proving that there is no direct correlation between the roughness parameters obtained from contact and non-contact measurements (Adamczak et al. 2015). Substantial differences were found between the roughness measurement results by stylus profiler, AFM and non-contact optical profiler (Poon and Bhushan 1995). Similarly, 3D characteristics of the surfaces were different for confocal laser scanning and stylus techniques (Wennenberg et al. 1996), and further differences were generated by different filters (Dimkovski et al. 2016). Thus, the experimental relative error of method $\delta_{e m}$ should be understood only as a helpful aid in the evaluation of the applicability, but not as a main criterion. 
Fig. 8 Measurement results for the sample no. 2: a with WYKO NT 1100 , b with air gauge no. 1 for different feeding pressures and with Perthen S8P, c $W t$, $P t, R a, R q$ and $R z$ parameters obtained from air gauges with reference to Perthen S8P (a)
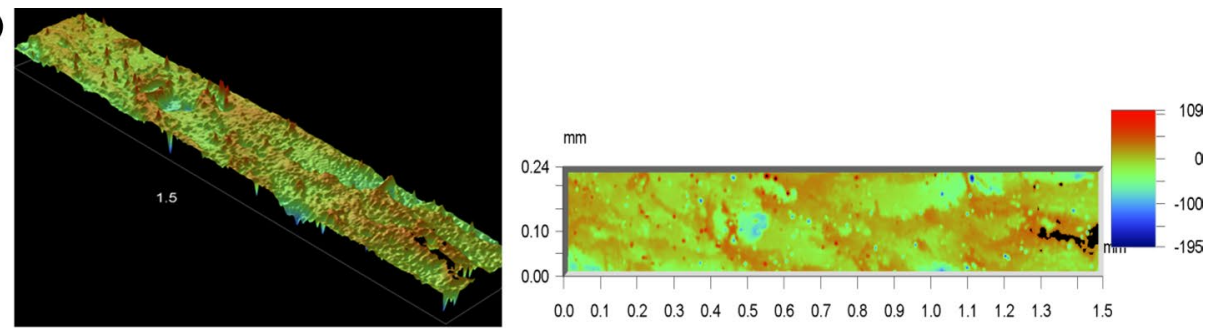

(b)
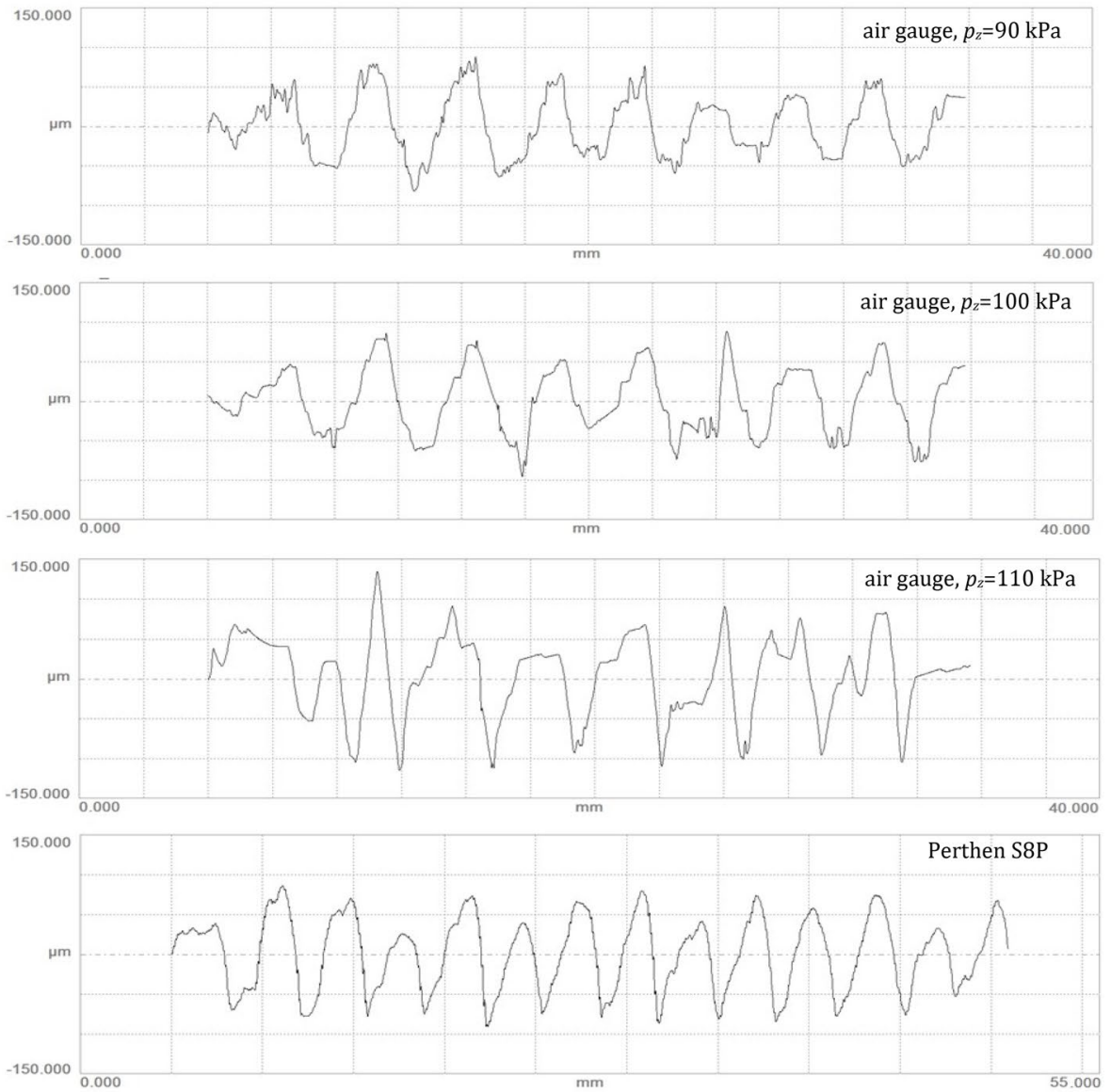

(c)
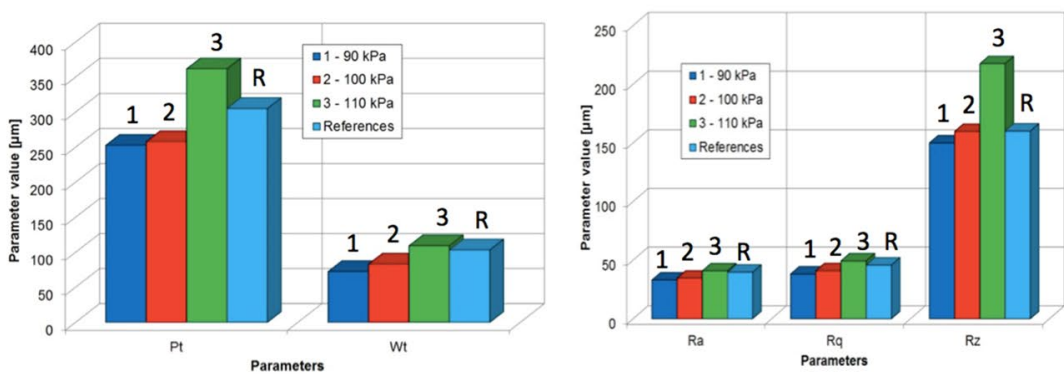

Air gauge no. 2 with higher sensitivity was rather ineffective in sample no. 1 measurement. Thus, it can be stated that the air gauges of lower sensitivity like no. 2 with $K=0.6 \mathrm{kPa} / \mu \mathrm{m}$ may rather be applied to the surfaces of beech wood shaped by the frame saw similar to sample no. 2 . In the case of sample no. 1, machined by a band saw, measurement by higher sensitivity air gauge no. 1 of some parameters is less accurate than for others. Namely, waviness 


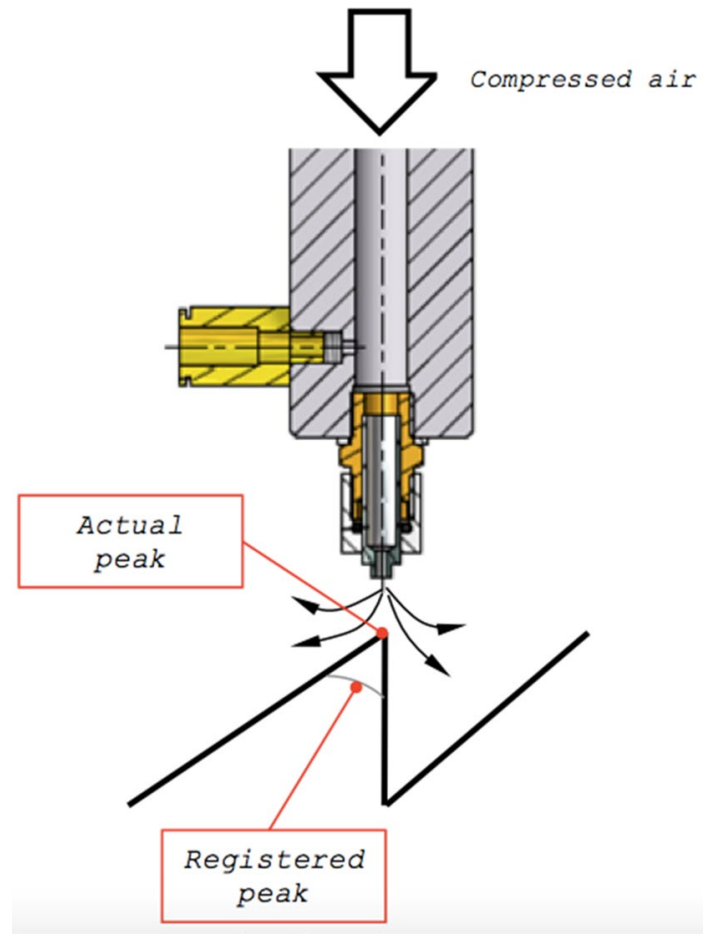

Fig. 9 Measurement of the sharp peak with the air gauge

$W t$ and $R z$ had larger relative error (35 and 20\%, respectively), while $R a$ and $R q$ results had very small ones, 1.7 and $3 \%$, respectively.

In the practical applications, the results of air gauge measurement should be related to the initial settings, not to other devices. Open jet type air gauges provide the dimension measured from an area on the object surface, which is distinct from the single point referencing as in the case of contact type gauges (Farago and Curtis 2014). Thus, in order to perform correct measurement, the reference surface must be prepared and its roughness parameters measured with pneumatic follower should be treated as a reference point for all subsequent measurements.
Since uncertainty of the air gauging was discussed elsewhere (Jermak et al. 2017a), the present research focused only on the air gauge ability to reproduce the measured profile. Figure 12 presents the example of profiles obtained from 5 repetitions of the measurement in the same conditions, on the same path, in a short time span.

It should be emphasized, that the main assumptions applicable to the wooden industry were challenged and the follower-type device based on air gauging can be applied alternatively to the surface quality assessment, especially for waviness parameter. In future researches, the ability of the device to detect high peaks will be checked.

\section{Conclusion}

A prototype of the non-contact surface quality assessment based on air gauges proved to be suitable for some specific measurement tasks. Its merits were low price and low exploitation costs (especially with smaller diameters of nozzles), as well as the non-contact measurement with its insensitivity to dirt and to optical characteristics of the surface (reflections etc.).

In most cases the differences between the pneumatic measurement and profilometer were small enough to be accepted. In the case of the known specific task and two or three parameters to be identified, the appropriate air gauges could be selected to ensure the required accuracy. Since it is difficult to compare the results with contact measurement methods, in practice, roughness assessment should be made using setting masters prepared as the reference surfaces for the series of measurements.

The pneumatic follower proved to be a satisfactorily accurate non-contact device for wooden surface assessment, and further investigation may improve its characteristics.
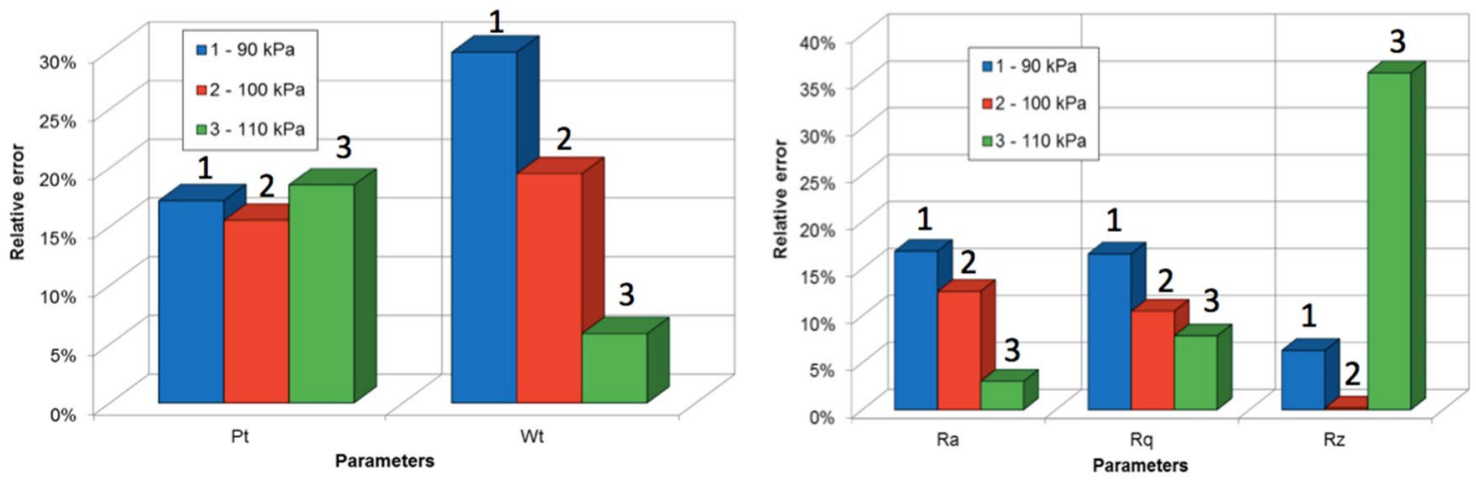

Fig. 10 Relative errors of different parameters obtained with air gauge no. 1 fed with different pressures $p_{z}$ from 90 to $110 \mathrm{kPa}$ 


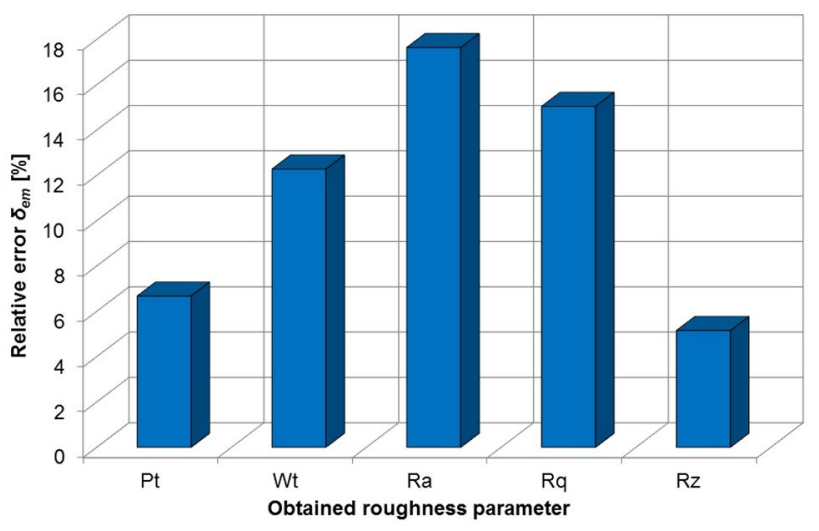

Fig. 11 Relative errors of different roughness parameters of sample no. 2 obtained with the air gauge No. 1

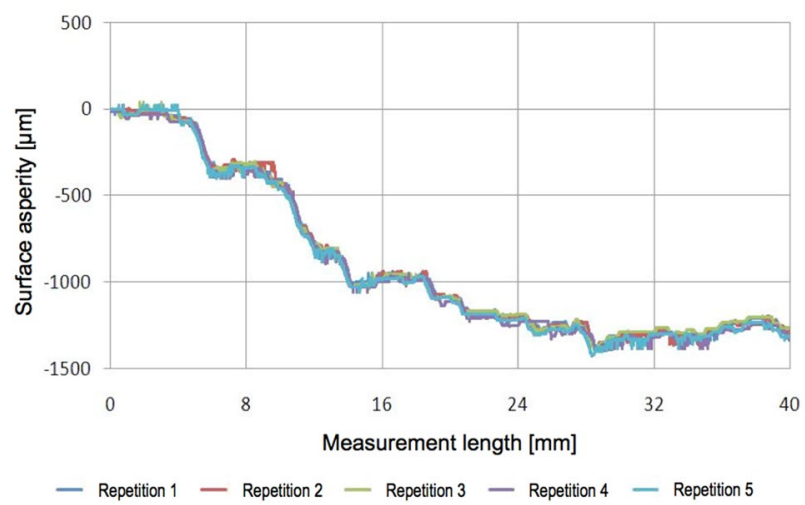

Fig. 12 Example of the profiles obtained from the same path with 5 repetitions

Acknowledgements The paper is an expanded version of an abstract presented at the XXII IMEKO World Congress, 3rd-6th September 2018, Belfast. The authors express their gratitude to MSc Eng. Marcin Łepecki for his involvement in constructional works on the device prototype and in laboratory measurements and to Prof. Piotr Pohl, Professor emeritus of University of Life Sciences in Poznan for his important contribution.

\section{Compliance with ethical standards}

Conflict of interest On behalf of all authors, the corresponding author states that there is no conflict of interest.

Open Access This article is licensed under a Creative Commons Attribution 4.0 International License, which permits use, sharing, adaptation, distribution and reproduction in any medium or format, as long as you give appropriate credit to the original author(s) and the source, provide a link to the Creative Commons licence, and indicate if changes were made. The images or other third party material in this article are included in the article's Creative Commons licence, unless indicated otherwise in a credit line to the material. If material is not included in the article's Creative Commons licence and your intended use is not permitted by statutory regulation or exceeds the permitted use, you will need to obtain permission directly from the copyright holder. To view a copy of this licence, visit http://creativecommons.org/licenses/by/4.0/.

\section{References}

Adamczak S (2008) Measurement of surface geometry. WNT, Warsaw (in Polish)

Adamczak S, Miller T, Swiderski J, Wieczorowski M, Majchrowski R, Letocha A (2015) The assumptions to credibility assessment of surface topography measurements in various scales. Mechanik 3:81-87

Aguilera A, Barros JL (2010) Sound pressure as a tool in the assessment of the surface roughness on medium density fibreboard rip sawing process. Maderas Ciencia y tecnología 12(3):159-169. https://doi.org/10.4067/S0718-221X2010000300001

Aguilera A, Rolleri A, Burgos F (2016) Cutting distance as factor to evaluate the quality of wood machined surfaces: a preliminary study. Maderas Ciencia y tecnología 18(1):3-8. https://doi. org/10.4067/S0718-221X2016005000001

Balakshin OB (1964) Automation of pneumatic dimensional control in industry. Mashinostroyenie, Moscow (in Russian)

Bewoor AK, Kulkarni VA (2009) Metrology and measurement. Tata McGraw-Hill, New Delhi

Csanády E, Magoss E, Tolvaj L (2015) Quality of machined wood surfaces. Springer, Cham

Dimkovski Z, Tomanik E, Profito F (2016) Influence of measurement and filtering type on friction predictions between cylinder liner and oil control ring. Tribol Int 100:7-17. https://doi. org/10.1016/j.triboint.2015.10.014

Farago FT, Curtis MA (2014) Handbook of dimensional measurement, 5th edn. Industrial Press Inc., New York

Fullmer IH (1966) Dimensional Metrology, Subject-classified with Abstracts Through 1964. Washington, US Department of Commerce, National Bureau of Standards

Gurau L, Mansfield-Williams HD, Irle MA (2001) A comparison of laser triangulation and stylus scanning for measuring the roughness of sanded wood surfaces. In: Proceedings of the 5th international conference on the development of wood science, wood technology and forestry, Ljubljana, Slovenia, September 2001, pp 299-310

Hu C, Afzal MT (2005) Automatic measurement of wood surface roughness by laser imaging. Part I: development of laser imaging system. For Prod J 55(12):158-163

ISO 4287 (1997) Geometrical Product Specification (GPS)—surface texture: profile method: terms, definitions and surface texture parameters. International Organization of Standardization, Geneva

Jakubiec W, Malinowski J (2009) Dimensional Metrology. WNT, Warsaw (in Polish)

Jarusombuti S, Ayrilmis N (2011) Surface characteristics and overlaying properties of flat-pressed wood plastic composites. Eur J Wood Prod 69:375-382. https://doi.org/10.1007/s00107-010-0440-z

Jermak CJ, Rucki M (2016a) Dynamics of the non-contact roundness measurement with air gages. Acta Mechanica et Automatica 10(3):227-232. https://doi.org/10.1515/ama-2016-0035

Jermak CJ, Rucki M (2016b) Static characteristics of air gauges applied in the roundness assessment. Metrol Meas Syst 23(1):85-96. https ://doi.org/10.1515/mms-2016-0009

Jermak CJ, Jakubowicz M, Derezynski J, Rucki M (2017a) Uncertainty of the air gauge test rig. Int J Precis Eng Manuf 18(4):479-485. https://doi.org/10.1007/s12541-017-0058-8

Jermak CJ, Pohl P, Rucki M, Jakubowicz M (2017b) Pneumatic follower for the wooden surface quality assessment. In: Proceedings 
of the XXII IMEKO World Congress, 3rd-6th September 2018, Belfast, accessible at https://www.imeko2018.org/abstracts/ IMEKO18-353.PDF

Jermak CJ, Piatkowski R, Derezynski J, Rucki M (2017) Comparison of the models of the air gauge static characteristics. Arch Mech Eng 44(1):93-110. https://doi.org/10.1515/meceng-2017-0006

Kilic M, Salim H, Burdurlu E (2006) Effect of machining on surface roughness of wood. Build Environ 41:1074-1078. https://doi. org/10.1016/j.buildenv.2005.05.008

Leach R (2001) The measurement of surface texture using stylus instruments. National Physical Laboratory, Teddington

Meng YS, Shan Y, Kang JS (2014) Measurement and characterization of precision $7 \mathrm{~mm}$ and $3.5 \mathrm{~mm}$ coaxial air lines at NMC, A*STAR. In: Proceedings of 29th conference on precision electromagnetic measurements (CPEM 2014), 24-29 Aug. 2014, Rio de Janeiro, Brazil. https://doi.org/10.1109/CPEM.2014.6898517

Molnar Z, Nemeth G, Hejja S, Magoss E, Tatai S (2017) The effect of the position of 2D roughness measurement on the roughness parameters by natural wood material. Wood Res 62(6):895-904

Pawlus P (2004) Mechanical filtration of surface profiles. Measurement 35(4):325-341. https://doi.org/10.1016/j.measuremen t.2004.03.007

Peng X, Zhang Z (2019) Surface properties of different natural precious decorative veneers by plasma modification. Eur J Wood Prod 77:125. https://doi.org/10.1007/s00107-018-1355-3

Pohl P, Jermak C (2007) Directions of development of pneumatic measurement methods to be applied for roughness measurements of surfaces of wood and wood-based materials. Annals of Warsaw University of Life Sciences-SGGW. For Wood Technol 62:145-149

Poon CY, Bhushan B (1995) Comparison of surface roughness measurements by stylus profiler, AFM and non-contact optical profiler. Wear 190:76-88. https://doi.org/10.1016/0043-1648(95)06697-7

Raja J, Muralikrishnan B, Fu S (2002) Recent advances in separation of roughness, waviness and form. Precision Eng 26(2):222-235. https://doi.org/10.1016/S0141-6359(02)00103-4
Rucki M, Jermak CJ (2012) Dynamic properties of small chamber air gages. J Dyn Syst Meas Control. https://doi.org/10.1115/14005 043

Smith EH (1994) Mechanical engineer's reference book, 12th edn. Butterworth-Heinemann Ltd., Oxford

Souza AJ, Jeremias TD, Gonzalez AR, Amorim HJ (2019) Assessment of melamine-coated MDF surface finish after peripheral milling under different cutting conditions. Eur J Wood Prod 77:559-568. https://doi.org/10.1007/s00107-019-01413-y

Thoma H, Peri L, Lato E (2015) Evaluation of wood surface roughness depending on species characteristics. Maderas Ciencia y tecnología 17(2):285-292. https://doi.org/10.4067/S0718-221X2 015005000027

Townsend A, Senin N, Blunt L, Leach RK, Taylor JS (2016) Surface texture metrology for metal additive manufacturing: a review. Precis Eng 46:34-47. https://doi.org/10.1016/j.precisione ng.2016.06.001

Wennenberg A, Ohlsson R, Rosen BG, Andersson B (1996) Characterizing three-dimensional topography of engineering and biomaterial surfaces by confocal laser scanning and stylus techniques. Med Eng Phys 18:548-556

Wieczorowski M (2013) Metrology of surface asperities: methods and systems. Wyd Zapol, Szczecin (in Polish)

Zelczak A (2002) Pneumatic dimensional measurement. WKL, Warsaw (in Polish)

Zhong ZW, Hiziroglu S, Chan CTM (2013) Measurement of the surface roughness of wood based materials used in furniture manufacture. Measurement 46(4):1482-1487. https://doi.org/10.1016/j.measu rement.2012.11.041

Publisher's Note Springer Nature remains neutral with regard to jurisdictional claims in published maps and institutional affiliations. 